Sakarya Üniversitesi İlahiyat Fakültesi Dergisi

Journal of Sakarya University Faculty of Theology

ISSN: 2146-9806 | e-ISSN: 1304-6535

Cilt/Volume: 22, Say1/Issue: 41, Y11/Year: 2020 (Haziran/June)

\title{
Bağımsızlık Yıllarında Kırgızistan Okullarında Din Dersi Denemeleri ve Son Dönemdeki Gelişmeler
}

Attempts to Introduce Religion Courses in Schools of Kyrgyzstan in the Years of Independence and Latest Developments

\section{Cazgül Colaliyeva}

Arş. Gör., Kırgızistan-Türkiye Manas Üniversitesi, İlahiyat Fakültesi, Din Bilimleri Bölümü - Res. Asst., Kyrgyz-Turkish Manas University, Faculty of Theology, Department of Religious Studies.

cazgül.colaliyeva@manas.edu.kg

https://orcid.org/0000-0003-2331-7951

\section{Makale Bilgisi - Article Information}

Makale Türü/Article Type: Araştırma Makalesi/ Research Article

Geliş Tarihi/Date Received: 09/01/2020

Kabul Tarihi/Date Accepted: 28/04/2020

Yayın Tarihi/Date Published: 15/06/2020

Atıf/Citation: Colaliyeva, Cazgül. "Bağımsızlık Yıllarında Kırgızistan Okullarında Din Dersi Denemeleri ve Son Dönemdeki Gelişmeler". Sakarya Üniversitesi İlahiyat Fakültesi Dergisi 22/41 (2020): 173-196. https://doi.org/10.17335/sakaifd.672546

İntihal: Bu makale, iThenticate yazılımı ile taranmış ve intihal tespit edilmemiştir. Plagiarism: This article has been scanned by iThenticate and no plagiarism detected.

Copyright () Published by Sakarya Üniversitesi İlahiyat Fakültesi - Sakarya University Faculty of Theology, Sakarya/Turkey. 


\title{
Bağımsızlık Yıllarında Kırgızistan Okullarında Din Dersi Denemeleri ve Son Dönemdeki Gelişmeler
}

\section{öz}

Kırgızistan 31 Ağustos 1991 tarihinde bağımsızlığına ulaşmış bir Orta Asya ülkesidir. Bu tarihten itibaren ülkede din-devlet ilişkileri yeniden yapılanma evresine girmiştir. Bağımsızlıkla birlikte Kırgızistan'ın tarihsel kimliği, dini inançları, örf ve adetleri konusunda toplumda bir farkındalık ortaya çıkmıştır. Demokrasi yolunda yeniden adım atmaya başlayan ülkede bir yandan "laiklik", "din ve vicdan özgürlüğü" gibi yeni kavramlar etkin bir şekilde kullanılmaya başlanmış, diğer yandan ise, örgün eğitim kurumlarında din eğitiminin meşruiyeti akademik ve siyasi çevrelerin sıklıkla tartıştığı konuların içinde yer almıştır. Günümüz Kırgızistan'ında örgün din eğitimindeki birtakım gelişmelerden bahsetmek mümkündür. Özellikle, okulda din dersi denemeleri ayrıca incelemeye değer bir konudur. İşte bu makalede bağımsızlık sonrası Kırgızistan'daki dini durum genel olarak ele alındıktan sonra, devlet okullarındaki din dersi denemeleri incelenmiştir. İlk olarak, bağımsızlığın ilk yıllarında bazı okullarda verilen "Iyman" (İman) dersi ve günümüzde zorunlu ders olarak ülkenin tüm okullarında okutulan "Adep" (Edep) dersi amaç ve muhteva yönünden ele alınmıştır. Bunun yanı sıra, 2016-2017 eğitim-öğretim yılından itibaren pilot uygulama olarak okutulmakta olan "Din Madaniyatının Tarıhı" (Din Kültürü Tarihi) dersi amaç, muhteva, ders öğretmeni, derse ayrılan süre gibi konular açısından analiz edilmiştir.

Anahtar Kelimeler: Din Eğitimi, Kırgızistan, Örgün Din Eğitimi, Din Dersi.

\section{Attempts to Introduce Religion Courses in Schools of Kyrgyzstan in the Ye- ars of Independence and Latest Developments}

\begin{abstract}
Kyrgyzstan is a Central Asian country that became independent on August 31, 1991. From this date, religion-state relations in the country have entered into a phase of restructuring. With independence, there have been an awareness of historical identity, religious beliefs, customs and traditions among Kyrgyz people. On the one hand, new concepts such as secularism and freedom of religion and conscience have begun to be used actively in the country, and on the other hand, the legitimacy of religious education in formal education institutions have begun to be discussed frequently by academics and politicians. Today we can see some developments in formal religious education in Kyrgyzstan. Especially, there have been several attemts of teaching religion courses at public schools of Kyrgyzstan. So in this article, religion courses in public schools of Kyrgyzstan are examined. In particular, the "Iyman" course, which was taught during the first years of independence and the "Adep" course which was introduced as a compulsory subject in public schools in 2004, were analysed in terms of purpose and content. In addition, the "History of Religious Culture" course, which has been taught as a pilot project since the 2016-2017 academic year, is analyzed in terms of purpose, content, course teacher and time allocated to the course.
\end{abstract}

[You may find an extended abstract of this article after the bibliography.]

Keywords: Religious Education, Kyrgyzstan, Formal Religious Education, Religious Course.

\section{Giriş}

Bağımsızlığın ilanı, Kırgızistan'ın sosyo-ekonomik, siyasi ve kültürel alanında bir dönüm noktası olmuştur. Özellikle din müessesesinde önemli gelişmeler yaşanmıştır. Bağımsızlığın ilk günlerinden itibaren Kırgız yöneticileri arasında din ve vicdan özgürlüğü ile ilgili konular hararetli bir şekilde tartışılmaya başlamıştır. Devlet adamlarının dinle ilgili genel tutumu, Sovyet döneminde dine karşı uygulanan baskının yanlış olduğunun vurgulanması ve dinin toplumsal rolünün önemsenmesi şeklinde ortaya çıkmıştır. Bağımsızlık 
döneminin ilk Cumhurbaşkanı Askar Akaev bir konuşmasında şöyle demiştir: "Milletimizin önünde duran hedeflerin gerçekleşmesinde dinin ve dinî müesseselerin rolü büyüktür. İslâm'ın toplumumuzdaki etkisi gittikçe artmaktadır. Devletimiz düzenli ve belli çerçeve içerisinde yapılan İslâmî faaliyetlere destek verecektir..." ${ }^{1} \mathrm{Bu}$ ifadeler, yeni yönetimin dini konudaki yaklaşımını yansıtmaktadır. Bu tarihten sonra, din-devlet ilişkileri demokrasi prensiplerine uygun bir şekilde birtakım ulusal ve uluslararası kanun, anlaşma ve kararnamelerle hukuki açıdan düzenlenmeye başlanmıştır. Ayrıca, Anayasa'nın ilk maddelerinde ülkenin laikliği benimsediği vurgulanmıştır. Bu hukuki düzenlemeler vatandaşların dini alandaki özgürlüklerini sağlamıştır. Günümüze kadar genel olarak dini alanda nicel ve nitel anlamda ciddi gelişmelerin yer aldığını söyleyebiliriz. Yakın zamana geldiğinde, Kırgız halkının dindarlaşma düzeyinde de hızlı bir artış söz konusudur, denebilir. Böylece, halkın dînî bilgi düzeyi, dînî temayülleri, dînî akım ve gruplara bakış açıları, dînî kişi ve kurumlara yaklaşımları, dînî emir ve yasaklara karşı tutumları, dînî ibadetleri ifa gibi konularda önemli ölçüde gelişme olduğu söylenebilir. ${ }^{2}$

Öte yandan, Kırgızistan'da din eğitimine gelince, örgün eğitim kurumlarında din eğitiminin verilip verilmemesi sürekli tartışma konusu olmuştur. Tartışmalar, "laiklik" kavramının ülkedeki uygulanış biçiminden kaynaklanmaktadır. Örgün eğitim kurumlarında din eğitiminin verilmesine karşı olanlar, ülkenin laik yapısı gereği, devlet kurumlarında din eğitiminin verilmesinin mümkün olmadığını ileri sürmektedirler. Bu kesimin fikrine göre, laik devlette din ile devlet kurumları birbirinden ayrı olması gerekmektedir. Din eğitiminin devlet kurumlarında verilmesi gerektiğini savunanlar ise laikliği, "devletin ülkedeki tüm dini gruplara eşit tutum sergilemesi" şeklinde yorumlamaktadırlar. Bu sebeple devletin vatandaşlarına din eğitimini doğru bir şekilde vermesi beklenmektedir. Bu tür tartışmalara rağmen, özellikle son yıllarda ülkenin resmi eğitim kurumlarında din eğitiminin sağlanması ülke güvenliği için önemli bir faktör olduğuna dair farkındalık oluşmuştur. Günümüzde devlet okullarında "Adep" (Edep) dersi ve pilot uygulama olarak verilen "Din Madaniyatının Tarıhı" (Din Kültürü Tarihi) dersi aracılığıyla din eğitimi verildiği söylenebilir. Makalemizin esas amacı bağımsızlık yıllarından bugüne kadar uygulanan din dersi denemelerini detaylı bir şekilde analiz etmektir. Bu bağlamda önce Kırgızistan'da din-devlet ilişikileri ve dini durum ele alınacaktır. Sonrasında, Kırgızistan'da din dersi denemeleri incelenecektir; ilk olarak ülkenin bazı okullarında seçmeli olarak okutulan "Iyman" (İman) dersi ve bu dersi okutma sürecinde karşılaşılan problemler açıklanacaktır.

1 Konuşmanın alındığı kaynak: Mametbek Mırzabaev, Kırgızitan'da Din-Devlet İlişkileri (Ankara: Ankara Üniversitesi, Sosyal Bilimler Enstitüsü, Doktora Tezi, 2009), 79-80.

2 Hidayet Aydar, "Kırgızistan'da Dindarlaşma Tirendi; Problemler, Öneriler", Türk Dünyası Bilgeler Zirvesi: Gönül Sultanları Buluşması Sempozyum Bildiri Kitabı (Eskişehir: Türk Dünyası Kültür Başkenti Ajansı, 2014), 497-536. 
Sonraki kısımda İman dersinin değiştirilmiş hali olan ve devlet okullarında zorunlu olarak okutulan "Adep" (Edep) dersi ele alınarak, dersin amacı ve muhtevası incelenecektir. Son olarak da, şu an bazı okullarda pilot uygulama olarak verilen Din Kültürü Tarihi dersi amaç, muhteva, derse ayrılan süre, ders öğretmeni gibi hususlar açısından ele alınacaktır.

Kırgızistan'daki örgün din eğitimini konu edinen birçok çalışma mevcuttur. Bunların içinden Dilaram Akramova ve Elvin Yusubov'a ait tezler makalemizin konusuna yakınlığı açısından büyük önem arzetmektedir. Bununla birlikte, Kırgızistan' daki örgün din eğitiminin durumunu ve bu alandaki sorunları inceleyen birkaç makale, bir proje ve bir kitap mevcuttur. ${ }^{3}$ Bu çalışmalarda ülkedeki örgün din eğitiminin tüm basamakları geniş bir şekilde analiz edilmiştir, amcak okulda din eğitimi konusu yüzeysel olarak incelenmiştir. Ayrıca, bu alanda yer alan son dönem gelişmeler de bu çalışmalarda ele alınmamıştır. Kırgızistan'ın okullarında din eğitimi denemeleri ve bu alanda yer alan son dönem gelişmeleri ele aldığ 1 yönüyle bu makale, yukarıda belirtilen çalışmalardan farklı olacaktır. Bu özelliklerden dolayı makalenin özgün ve alana katkı sağlayacak mahiyette olduğu söylenebilir.

\section{Kırgızistan'da Dini Durum ve Din-Devlet İlişkileri}

Sovyet döneminde yasaklanan din müessesesi, Kırgızistan'ın bağımsızlığı kazanmasıyla özgürlüğe kavuşmuştur. Kırgız toplumu seksen yıldan fazla Komünist sisteminin baskıcı politikası altında olmasına rağmen, Müslüman kimliğini korumayı başarmıştır. İlk hükümetin din alanındaki tutumu da oldukça olumlu olup, din ve vicdan özgürlüğü yüksek düzeydeki hukuki belgelerle garanti altına alınmıştır. Bağımsızlık ilanından dört ay sonra, Kırgız Cumhuriyeti Yüksek Konseyi 16 Aralık 1991 tarihinde din-devlet ilişkilerini hukuki düzeyde düzenleme adına “Vicdan Özgürlüğü ve Dini Kurulumlar

3 Kırgızistan' da örgün din eğitimi konusunda yapılan çalışmalar için bk. Ahmet Cihan, "Kırgızistan'da Din Eğitimi Veren Kurumlar", İslam Araştırmaları Dergisi 14 (2005), 111-124; Dilaram Akramova, Kırgızistan'da Orto Mekteplerdeki “Adep Sabagı" Dersinde Din Ĕ̆itimi İle İlgili Amaçların Gerçekleşme Düzeyi (Oş Örneği) (Ankara: Ankara Üniversitesi, Sosyal Bilimler Enstitüsü, Doktora Tezi, 2006); Suat Cebeci, Kırgızistan'da Dini Durum ve Din Eğitimi: Durum Analizi ve Öneriler, Araştırma Raporu (Kırgızistan-Türkiye Manas Üniversitesi, 2014); Suat Cebeci, "Kırgızistan'da Dini Durum ve Sovyet Sonrası Dini Gelişmeyi Besleyen Etkenler", $M A$ NAS Sosyal Araştırmalar Dergisi 5/3 (2016), 103-117; Elvin Yusubov, Kırgızistan'da Din Eğitimi (İstanbul: Marmara Üniversitesi, Sosyal Bilimler Enstitüsü, Doktora Tezi, 2016); Hamza Aktaş, "Kırgızistan' da Son Dönem Din Eğitimi Gelişmeleri", Akademik Sosyal Araştırmalar Dergisi 4/36 (Aralık 2016), 233-257; Mustafa Köylü - Sayfulla Bazarkulov, Din pedagogikası (Bişkek: Kırgız-Türk "Manas” Universiteti basılmaları, 2018); Cazgül Colaliyeva, "Din Öğretimi Temelleri: Kırgızistan Örneği", MANAS Sosyal Araştırmalar Dergisi 7/3 (Ăgustos 2018), 279-295; Cazgül Colaliyeva, Kırgızistan Liselerinde Okutulan "Din Kültürü Tarihi” Dersi Programının Incelenmesi: Bişkek Örneği (Kırgızistan-Türkiye Manas Üniversitesi, Sosyal Bilimler Enstitüsü, Yüksek Lisans Tezi, 2018). 
ile İlgili" (657-XII) Kanunu kabul etmiştir. Bu kanun, hangi dini inançtan olursa olsun, Kırgızistan vatandaşlarının dini alandaki hak ve özgürlüklerini güvence altına almaktadır. Bu durum, Kırgızistan'ın yeni dönemde özgürlükçü, demokratik ve laik bir devlet yapısını benimsediğini göstermektedir. ${ }^{4}$ 1993 yılında Kırgız Cumhuriyeti'nin Anayasası kabul edilmiştir. Anayasa'da, Kırgız Cumhuriyeti'nin temel yapılanma biçimi, "laik, hukuk devleti temeline dayalı egemen, üniter ve demokratik bir Cumhuriyet" 5 olarak tanımlanmıştır. Böylece Anayasa'nın ilk maddesinde, Kırgız Cumhuriyeti'nin din-devlet ilişkisinde laikliği benimsediği açıkça belirtilmiştir.

Dini alandaki hukuki çerçeveye insan hakları ile ilgili uluslararası anlaşmalar da katkı sağlamıştır. Kırgız Cumhuriyeti, İnsan Hakları Evrensel Beyannamesi başta olmak üzere, Avrupa Parlamentosunun insan haklarıyla ilgili kararları, Sivil ve Siyasi Haklarla İlgili Uluslararası Paktı ve Avrupa Güvenlik ve İşbirliği Teşkilatı'nın getirdiği sorumlulukları üstlenmiştir. Birleşmiş Milletler Teşkilatı (BM) üyesi olarak da "İnsan Hakları ve Temel Özgürlükler Alanındaki Uluslararası Sorumluluklar ile İlgili BM Üyesi Ülkelerin Bildirgesi" ve BM İnsan Hakları ve Temel Özgürlükler ile İlgili Bildirgeyi kabul etmiştir. ${ }^{6}$

Dini özgürlüklerin Anayasa ve yasa güvencesine kavuşturulmuş olması ile yeni dönemde dini hareketlere hukuki bir zemin sağlanmıştır. Dini alandaki gelişmeleri takip etmek ve devletin dinle ilgili siyasetini yürütmek üzere 4 Mart 1996 tarihinde bugünkü adı "Kırg1z Cumhuriyeti Din İşleri Devlet Komisyonu" olan ve doğrudan Devlet Başkanına bağlı olarak görev yapan bir devlet kurumu kurulmuştur. Din Komisyonu, toplumda istikrarı korumak, dinî aşırılığı önlemek, farklı dinlerin müntesipleri arasında karşılıklı hoşgörünün kurulmasını sağlamak, toplumda manevî ve ahlâki temelleri güçlendirmek için çalışmaktadır. Bunun yanısıra Din Komisyonu, din ve dinî kurumlar ile ilgili meselelerde Anayasaya, kanunlara, hükümet ve Cumhurbaşkanı kararnamelerine uyulup uyulmadığını kontrol etmektedir. ${ }^{7}$ Bununla birlikte, Müslümanların her türlü dini ihtiyacını karşılamak amacıyla ülkede, 1993 yılında "Kırgızistan Müslümanları Dini İdaresi" (Muftiyat) kurulmuştur. Kırgızistan Müslümanları Dini İdaresi (Muftiyat), ülke sınırları içinde, İs-

5 Konstitutsiya Kırgızskoy Respubliki ot 27 iyunya 2010 goda. Statya 1, punkt 1. (Erişim 22 Mayıs 2018).

6 Mirzabaev, Kırgızitan'da Din-Devlet İlişkileri, 84/

7 Yusubov, Kırgızistan'da Din Eğitimi, 67. 
lam'la ilgili tüm dini kurumları, faaliyet yürüten din eğitimi merkezlerini, camileri, cemaatleri ve tüm ülke Müslümanlarını bir araya getiren bir kurumdur. ${ }^{8}$

Son yıllarda Kırgızistan'da din-devlet ilişkilerinin yeni bir döneme girdiği görülmektedir. Ülkedeki din alanında sergilenen özgürlük ve kontrolsüzlüğün doğurduğu bazı zararlı sonuçlar, devletin din alanında yeni düzenlemelere gitmesine neden olmuştur. Bundan dolayı 3 Şubat 2014 yılında Kırgız Cumhuriyeti'nin Milli Güvenlik Kurulu toplantısında, dini alanda devlet politikasının yeniden gözden geçirilmesi ile ilgili konu yoğun bir şekilde tartışılmıştır. Toplantıda bağımsızlık sonrası devlet makamlarının, dini alanda denetim yapmamasının yanlış bir strateji olduğu dile getirilmiştir. Milli Güvenlik Kurulu toplantısının sonucu olarak 7 Şubat 2014 tarihinde açıklanan Cumhurbaşkanlığı Kararnamesinde; Müftülüğün ve diğer dini kuruluşların sıkı bir şekilde denetlenmesi, din ile ilgili konuları düzenleyen yasalarda ve politikalarda reform çalışmalarının başlatılması, İslami din kurumlarına atanacak görevlilerin Ehli Sünnet-Hanefi-Maturidi inançta olmaları, ${ }^{9}$ ülkede kaliteli din eğitimi sisteminin geliştirilmesi kararları kabul edilmiştir. Bu kararlar, Kırgız Devletinin ülkedeki dini gelişmeler konusundaki tutumu, özellikle de İslami alandaki mezhep tercihi bakımından son derece önemlidir. Kurul toplantısında din eğitiminin ve özellikle okullardaki din eğitiminin mahiyeti tartışılmış ve sonradan kabul edilen Kararnamede müstakil bir madde olarak konulmuştur. Ayrıca bu gelişmeler sonucunda Kırgız Cumhuriyeti Cumhurbaşkanı'nın 14 Kasım 2014 tarihli Kararnamesiyle "Kırgız Cumhuriyeti'nin 2014-2020 Yılları için Din Alanındaki Devlet Politikasının Konsepti" onaylanmiştir. ${ }^{10}$

Adı geçen tüm düzenlemeler, dini alandaki kurumsal işleyişin gün geçtikçe devlet tarafından denetim altına alındığını göstermektedir. Daha önce devletin anayasal çerçeve içerisinde dini dinamiklere pek fazla müdahalesi söz konusu olmazken, son dönemlerde bu durumun değiştiği anlaşılmaktadır. Dolayısıyla kontrolsüz özgürlüklerin ve devletin bu konuyla daha işin başından ilgilenmemesinin sonradan birtakım sorunlara yol açtı̆̆ı, yaşanarak tecrübe edilmiştir. Toplumun dini açıdan istenmeyen fikir ve akımlara yönelmesi ve bu konuda yanlış uygulamalar yapması, neticede devlet açısından

8 Kırgızistan Müslümanları Dini İdaresi hakkında geniş bilgi için bk. Bakıt Murzaraimov-Mustafa Köylü, "Bağımsızlık Sonrası Kırgızistan'da Yaygın Din Eğitimi Faaliyetleri ve Camiler", Cumhuriyet Ilahiyat Dergisi 23/1 (Haziran 2019), 193-211.

9 Cebeci, "Kırgızistan'da Dini Durum ve Sovyet Sonrası Dini Gelişme”, 111

10 Bk. Ministerstvo Yustitsii Kırg1zskoy Respubliki, "Konseptsiya gosudarstvennoy politiki v religioznoy sfere na 2014-2020 god1, utverjdennaya Ukazom Prezidenta KR ot 14.11.2014 goda". (Erişim 06 Ocak 2020). 
problemler ortaya çıkarmıştır. Bu nedenle Kırgızistan hükümetleri bu gelişmeleri göz önünde bulundurarak, birtakım düzenlemeler yapmaktadır. ${ }^{11}$

Burada ülkedeki güçlü din-devlet işbirliğine engel olan bazı problemlerin olduğunu da belirtmek gerekir. Bu problemlerin başında "laiklik" kavramı üzerindeki tartışmalar gelmektedir. Din-devlet ilişkilerini araştıran Kırgız akademisyenler; "laik ülke” denince ne anlaşılması gerektiği konusunda ne akademik boyutta ne de anayasal boyutta ittifak olduğunu, "laikliğin" kriterleri ve sınırlarının belirlenmediğini ileri sürmektedirler. Bundan dolayı bazen toplumun laik ve ateist kesimiyle dindar kesimin arasında anlaşmazliklar otaya çıkmaktadır. Bazı devlet adamları, siyasetçiler ve toplumun belli kısmına göre laiklik, toplum hayatında dinin olmayışı ve dinsizlik anlamına gelmektedir.

Onların laiklik anlayışı, Sovyet dönemindeki "ateist laiklik" anlayışına benzemektedir. Devlet kurumları ise, laikliği dini kurumların devlet işlerine karışmaması olarak anlamaktadırlar. Bu gibi farklı yorumlardan dolayı devlet okullarına başörtü ile gelme, devlet kurumlarında ibadethanelerin bulunması, cami ve medreselerin devlet tarafından desteklenmesi gibi konularda zaman zaman tartışmalar yer almaktadır. ${ }^{12}$ Ayrıca "laik ülkenin resmi okullarında din dersinin okutulması mümkün müdür?" - sorusunun üzerinde tartışmalar yapılmaktadır. Bu bağlamda iki temel görüş vardır. İlk görüşe göre din dersinin okulda verilmesi laiklik ilkesine aykırıdır, çünkü laik ülkede din ile devlet ayrıdır. Diğer görüşe göre ise, laiklik gerekçesiyle din eğitimini ihmal etmek yanlıştır. Eğer devlet din eğitimini vermezse, bu vazifeyi radikal dini gruplar ve çeşitli akımlar yerine getirecektir. ${ }^{13} \mathrm{Bu}$ tarz tartışmalara rağmen, önceki paragraflarda da belirttiğimiz gibi, son yıllarda olumlu gelişmeler görülmektedir ve hükümet bu tür anlaşmazlıkların çözülmesinde etkin rolü üstlenmeye çalışmaktadır. Akademisyenler ve toplumun çoğunluğunun fikrine göre, sağlıklı din eğitimi vermenin en etkili yolu, devlet okullarında din dersini okutmaktır. ${ }^{14}$

\section{Kırgızistan Okullarında Din Dersi Denemeleri}

Bağımsızlığın ilk yıllarında Kırgızistan okullarında din eğitimi konusu en önemli konulardan biri olmuştur. Bir taraftan halkın yoğun bir şekilde dine yönelmesi, diğer taraftan yeni hükümetin din konusundaki liberal yaklaşımı

11 Aktaş, "Kırgızistan'da Son Dönem Din Eğitimi Gelişmeleri”, 243.

12 Z. D. Çotayev, "Vliyaniye religiyoznogo faktora na sotsialno-politiçeskuyu situatsiyu v Kırg1zskoy Respublike: Sotsiologiçeskoe issledovaniye", (PDF: Gosudarstvennay komissiya po delam religiy Kırg1zskoy Respubliki, 2016), 35-38.

13 Intervyu Nurjigita Kadırbekova institutu Bulan, 12 fevralya, 2017. Bk. "Bulan” institut innovatsıy dlya ukrepleniya mira (BİUUM), Religioznoe obrazovaniye v Kırgızstane: Medrese nujdayutsya v sroönoy reforme (PDF: "Bulan" institut innovatsıy dlya ukrepleniya mira, 2017), 18.

14 Cebeci, Kırgızistan'da Dini Durum ve Din Eğitimi, 39. 
tetikleyici faktör olmuştur. Günümüze kadar okulda din öğretimi uygulamalarının birkaç örneğinden söz etmek mümkündür.

İlk deneme olarak; 1992-2002 yılları arasında bazı Kırgızistan okullarında seçmeli olarak, 2002-2003 eğitim-öğretim yılında ise ülke genelinde zorunlu olarak okutulan İman dersini belirtebiliriz. ${ }^{15}$ İman dersi 2004 yılında Edep dersi olarak değiştirilmiştir ve günümüzde bu ders Kırgızistan'ın devlet okullarında zorunlu olarak okutulmaktadır. Son deneme, 2016-2017 eğitim-öğretim yılından itibaren bazı okullarda pilot uygulama olarak okutulan Din Kültürü Tarihi dersidir.

\section{1. İman Dersi (Iyman Sabag1)}

İman dersi 1992-1993 eğitim-öğretim yılından itibaren bazı okullarda seçmeli ders olarak okutulmaya başlanmıştır. Eğitim Bakanlığ 1 tarafından İman dersinin programı ve ders kitabı 2003 yılına kadar geliştirilememiştir, bu nedenle bu dersin içeriği okul idarelerinin takdirine bırakılmıştır. Böylece, 1990'dan 2003'e kadar, "Iyman" dersi farklı görüş ve içerikte okutulmuştur. Genel olarak, özel inisyatifle geliştirilen üç ${ }^{16}$ farklı İman dersi programı mevcuttu ve öğretmenler bu programlardan istifade ediyorlard1. "Iyman" kelimesinin anlam muğlaklığı bu dersin okutulmasındaki farklı uygulamalara yol açmıştır. Dersin adında geçen "Iyman" kavramı dini literatürdeki anlamı ile kullanılmamıştır. Türkçeye çevirildiğinde, "Iyman” kelimesi “iman, inanç" anlamına gelmektedir, ancak Kirg1zcada "Iyman" kelimesi vicdan, ahlak ve onur anlamını da içermektedir. Dolayısıyla, bazı okullarda İman dersi, İslâmi kavram ve düşüncelere ağırlık verilerek, bazılarında ise milli değerlere ağırlık verilerek okutulmuştur. Ders öğretmeni konusunda da farklı uygulamalar söz konusu olmuştur; mesela, bazı okullarda bu dersi din görevlileri vermiş, bazılarında ise edebiyat öğretmenleri vermiştir. ${ }^{17}$

Halk tarafından talep görmesine rağmen, sistematik programın, ders kitabının, konuya vakıf olan eğitimcilerin eksikliği ve diğer problemler neticesinde İman dersi istenen başarıyı gösterememiştir. Program düzensizliğini gidermek amacıyla, 2003 tarihinde Eğitim Bakanlığı tarafından İman dersinin resmi programı hazırlanmış olup, ülkenin tüm resmi okullarında haftada bir saat olmak üzere, zorunlu olarak okutulması kararlaştırılmıştır.

15 Köylü-Bazarkulov, Din pedagogikası, 158.

16 Bu programlar hakkında geniş bilgi için bk. I-X klasstarda 1yman sabagın okutuunun boljolduu programması (1992-1993-okuu j1lı üçün), tüz. B. Nurunbetov, M. Bayımbetov, A. Köçkönov, A. Tölönbaev (Oş, 1992). Dastan Sarıgulov, Iyman sabagı (tüpkü tüşünüktör) (Bişkek, 2004). Özübek Çotonov, Iyman sabagı: Filosofiyalık, publitsistikalık oy-tolgoolor (Bişkek: Mega mediya, 2004).

17 Bu konuda geniş bilgi için bk. Orhan Nadir Büyükalaca, Kırgızistan'da Din Eğitimi ve Kırgızistan Müslümanları Dini İdaresi (Ankara: Ankara Üniversitesi, Sosyal Bilimler Enstitüsü, Yüksek Lisans Tezi, 2003); Көйлү - Базаркулов, Дин педагогикасы, 158-159. 
Program 1-11 sınıflar için hazırlanmıştır. Programın muhtevasını milli eğitim, ahlak ilkeleri, manevi değerler, örf adetler, insani değer ve erdem konuları oluşturmuştur. Programda dini bilgiler de yer almıştır, ancak sistematik bir şekilde yer verilmemiştir. Dini bilgiler program boyunca serpiştirilmiş olup genel ahlak eğitimi çerçevesinde verilmiştir. Buna göre ders, din dersi olmaktan ziyade, genel kültür çerçevesi içinde ahlak eğitimini amaçlayan bir ders haline gelmiştir. Yeni programda iman dersinin zorunlu hale getirilmesiyle dersin adındaki "Iyman" kavramına yüklenen farklı anlamlar, dersin içeriğinin tartışılmasına neden olmuştur. Bazıları 'ıyman' kavramının inanç anlamına geldiğini, dolayısıyla ders içerisinde toplumun dini inancı ile ilgili konuların işlenmesi gerektiğini söylerken, bazıları da Kırgız dilinde imanın ahlak, onur ve kültür gibi anlamları içerdiği düşüncesinden hareketle, dersin kültürel konularla sınırlı olmasının laik eğitim anlayışına daha uygun düşeceğini belirtmişlerdir. ${ }^{18}$ Bu tartışmaların sonucu olarak, "Iyman" kelimesinin yanlış yorumlara neden olduğu, dini muhteva yüklenmiş olması gerekçesi ile Kırgızistan Bilimler Akademisinin teklifi ile İman desi Kırgızistan Milli Eğitim Bakanlığı tarafından 2004 tarihinde çıkartılan 545 Sayılı Özel Kanun doğrultusunda Edep dersi (Adep Sabagı) olarak değiştirilmiştir. ${ }^{19}$

\subsection{Edep Dersi (Adep Sabag1)}

Edep dersi Kırgızistan okullarında 2004-2005 eğitim-öğretim yılından itibaren zorunlu olarak okutulmaktadır. Öncelikle Edep dersinin İman dersi gibi bir din dersi olmayıp, genel kültür dersi olduğunu belirtmek gerekir. Ders müfredatında din ile ilgili konular oldukça az olup, İslam dini sadece kültürün bir unsuru olarak ele alınmaktadır. Dersin muhtevası Kırgız halkının milli değerleri, ahlaki ilkeleri, örf adetleri ile ilgili konuları içermektedir. Edep dersi toplumun ahlaki ve manevi değerlerinin tekrar güçlendirilmesini, öğrencilerin milli ideoloji ilkeleri doğrultusunda eğitilmesini, onlara temel ahlaki, manevi ve insani değerlerinin kazandırılmasını amaçlamaktadır. Edep dersinin başlıca amacı okul öğrencilerinin milli ideolojiye uygun ahlaki, manevi ve kültürel değerleri kazanmalarını sağlamaktır. Bu amaç öğrencilerde derin ahlaki şuur ve anlayışın oluşumu ve kazanımı, ahlaki ilkelerin öğretilmesi, günlük yaşantı ve ilişkilerde ahlaki ilkelerin uygulanması ile gerçekleştirilebilir. Edep dersinin ders olarak önemi şöyle ifade edilmiştir: “Dersin muhtevası Kırgız halkının yüzyıllar boyunca oluşturulan milli eğitim ahlak ilkeleri, örf adet, manevi değerleri ve bütün insani değer ve erdem konularından oluşmaktadır" .20

18 Yusubov, Kırgızistan'da Din Eğitimi, 99. Hüseyin Yılmaz, “Kırgızistan'da Misyonerlik ve Din Eğitimi", Cumhuriyet Üniversitesi İlahiyat Fakültesi Dergisi 11/1 (Haziran 2007), 113-114.

19 Akramova, Kırgızistan'da Orto Mekteplerdeki "Adep Sabagı", 26-27.

20 Akramova, Kırgızistan'da Orto Mekteplerdeki "Adep Sabagı", 28. 
Edep dersinde halkın asırlarca yaşattığ 1 ve nesilden nesle aktarageldiği geleneklerin, örf adetlerin ve manevî değerlerin öğrenciler tarafından benimsenmesi amaçlanmaktadır. Bundan dolayı dersin metodolojik kısmında sorucevap, münazara, beyin fırtınası, görüşme v.b. aktif yöntemlerin uygulanması önerilmektedir. Buna ilaveten, öğretmenler tecrübelerini öğrencilerle paylaşabilecek yaşlıları, ebeveynleri, el sanatları ustaları, bilim adamları ve akademisyenleri, manevî ve ahlâki yönden zengin olan insanları derse davet ederek, karşılıklı konuşma yöntemiyle ders yapabilirler. Değerlerin oluşması uzun ve çok çaba gerektiren bir süreç olması nedeniyle, Edep dersi öğretmenleri sürekli ebeveynlerle işbirliği içerisinde olmalıdırlar. ${ }^{21}$

Öğretim programı 1-11. sınıfları içine almaktadır. ${ }^{22}$ Her sınıfa haftada 1 saat olmak üzere senede 34 saat okutulmaktadır. Öğretim programı aşağıdaki üniteler şeklinde düzenlenmiştir:

1-4. Siniflar "Adep" ünitesi

5-7. Sinıflar "Miras" 23 ünitesi

8. Sinıf “İnsan" ünitesi

9. Sınıf "Aile" ünitesi

10. Sınıf "Halk Tanıma" ünitesi

\section{Sınıf “Kültür" ünitesi}

Edep dersinde kismen de olsa din ile ilgili konulara yer verilmektedir. Bu konuları aşağıdaki şekilde özetleyebiliriz:

1-4. siniflarda "Ahlak alfabesi", "Aile ahlâkı", "Oruç", "Dünya dinleri", "İslâm Ahlâkı" gibi konular yer almıştır. Ahlâk alfabesi konusunda vicdan, namus, ahlâk kavramları açıklanmıştır.

5-7. sınıfların "Miras" ünitesi şu dini konuları içermektedir: Oruç, orucun özellikleri ve oruç kavramının açıklanması. Ramazan ayında verilen fıtır sadakasının anlamı ve önemi. Yardımseverliğin önemi. Kutsal ziyaret yerleri ve türbeler (Manas türbesi, Burana Minaresi, Süleyman dağı, Taşrabat, Kurmanbeyin Koş Arık türbesi vb.) hakkında bilgi verilmesi. Hz. Muhammed'in "Yarın kıyamet kopacağını bilsen de fidan dik" hadisinin anlamı ve hadis ışığında konunun açıklanması.

21 Yusubov, Kırgızistan'da Din Eğitimi, 98-100.

222004 yılından 2012 yılına kadar Adep dersi 1. sınıftan 11. sınıfa kadar okutulmuştur, ancak 2012-2013 eğitim-öğretim yılında Adep dersi 9-11. sınıfların müfredat programından alınmıştır ve Adep dersine ait olan bazı konular İnsan ve Toplum, İktisada Giriş gibi derslerin içine entegre edilmiştir bk. Köylü -Bazarkulov, Din pedagogikası, 161-162.

23 Bu ünitede "miras" kelimesi mecazi anlamda kullanılmaktadır ve bir kuşağın kendinden sonraki kuşağa bıraktığı manevi değerler kastedilmektedir. Bu ünitede Kırgız halkının kültürel mirasları ele alınmıştır. 
Dokuzuncu sınıfta "Aile" ünitesinde, nikah konusuna yer verilmiş, onuncu sınıfta ise, Kırgız halkının eski geleneksel dinî inancı olan Tanrıcılık hakkında bilgi verilmiştir. Buna ilaveten, ünitede İslam'ın Kırgız toplumunun gelenek görenekleri ve dünyaya bakış anlayışı üzerindeki etkisi, önemi ve yeri anlatılmaktadır. Ayrıca, İslâm'ın eğitim ve ahlâk ilkeleri ve Hz. Muhammed'in hayatı ve örnek şahsiyeti işlenmektedir.

Son on birinci sınıfta din ile ilgili şu konular yer almaktadır: Kültürün bir unsuru olarak din (İslâm, Hiristiyanlık, Budizm ve Yahudilik dinleri) hakkında genel bilgiler ve bu dinlerin maddî ve manevî dünyaya getirdikleri kazanımları; İslâm dinînin kültürel, ahlâki ve manevî özellikleri; İnsanlığın kültürel ahlâki ve eğitsel zenginliği olarak hadisler ve Hz. Muhammed'in ahlâk ilkeleri hakkında bilgi verilmektedir. ${ }^{24}$

Yukarıda belirlendiği üzere, Edep dersi bir din dersi olmaktan ziyade, bir kültür dersidir. Bu derste işlenen konular, genel olarak öğrencilerin ahlaki yönden gelişmesine katkıda bulunabilecek konumdadır. Programda ne İslâm hakkında ne de diğer dinler hakkında yeterli ve sistemli bilgiler verilmektedir. Programda daha çok Kırgız atasözleri, gelenek ve örf-adetlere ağırlık verilmiştir. Ayrıca, bazı araştırmacıların tespitlerine istinaden, Edep dersi programının içeriği oluşturulurken, öğrencilerin gelişim psikolojisi dikkate alınmamıştır. Bu tespit dini içerikteki konular için özellikle geçerlidir. Şöyle ki, yukarıda verilen bilgilerden de anlaşılacağı üzere, 1.-4. sınıflarda "Ahlak", "Aile Ahlakı", "İslam Ahlakı" gibi soyut konular işlenmektedir. Meğerse, bu sınıflardaki öğrenciler (7-10 yaş arası) somut işlemler döneminde oldukları için, "ahlak" gibi soyut kavramı anlamaları mümkün değildir. Aynı zamanda, 3. sınıfta "Oruç" konusu işlenmektedir. Belirtilecek husus, İslam'ın diğger şartları hakkında bilgi verilmeden hemen "Oruç" konusu açıklanmaktadır. İslam'ın bir şartının başka şartlardan kopuk bir şekilde anlatılması yanlış alg1lamaları doğurabileceği açıktır. Buna ilaveten, 4. sınıflarda zor akademik dil ile İslam ilk başta olmak üzere, "Budizm" ve "Hristyanlık" hakkında bilgi verilmektedir. ${ }^{25}$ Bunun da eğitimsel ve metodolojik açıdan yanlış olduğunu belrtimek gerekir. Zira, öğrenciler için kendi dinleri hakkında yeterli bilgilere sahip olmadan diğer dinleri öğrenmeleri oldukça zordur. Bunlardan hareketle programın içeriği "yakında uzağa", "somuttan soyuta", "kolaydan zora" gibi ilkelere uygun olmadığını ileri sürmek mümkündür.

Ayrıca, Edep dersini verecek öğretmen konusunda da önemli eksiklikler mevcuttur. Zira bu derse büyük ölçüde Kırgız Dili ve Edebiyatı öğretmenleri ve bazen diğer branş hocaları girmektedir. Bu derse giren çok sayıdaki öğretmenlerin dinî bilgiye hakim olmadığını belirtmek gerekir. Bu nedenle bu dersin etkililiğini artırmak için en azından konuya vakıf olan ve daha önce bu

24 Yusubov, Kırgızistan'da Din Eğitimi, 103-109. Köylü -Bazarkulov, Din pedagogikası, 162.

25 Akramova, Kırgızistan'da Orto Mekteplerdeki "Adep Sabagı", 95-98. 
dersi okutan, manevî değerler, edebiyat, tarih ve felsefe konusunda bilgili olan insanlara emanet edilmesi uygun görülmektedir. ${ }^{26}$

Özet olarak şunları belirtmek mümkündür; Edep dersi öğrencilerin milli ve ahlaki gelişimi için önemli işlevler üstlenmektedir. Ancak, bu dersin öğrencilerin dini bilgilere olan ihtiyacını karşılamadığı bir gerçektir, zira Edep dersinde sistemsiz bir şekilde verilen bazı dini konular oldukça yetersiz kalmaktadır. Bunların doğal sonucu olarak son zamanlarda devlet okullarında din öğretimi verme hususu tekrar gündeme gelerek, önceki Kırg1z Cumhuriyeti Cumhurbaşkanı'nın inisyatifi ve bazı devlet kurumlarının katkılarıyla, 2016-2017 eğitim-öğretim yılından itibaren, ülkenin bazı okullarında Din Kültürü Tarihi adında yeni bir ders okutulmaya başlanmıştır. Makalenin bu kısmında bu derse ilişkili gelişmelere yer verilecektir.

\subsection{Din Kültürü Tarihi Dersi (Din Madaniyatının Tarıhı)}

Kırg1z Toplumunda dine olan yoğun ilgiyle birlikte, uluslararası terör örgütlerinin sebep olduğu tehditler, devletin resmî kurumlarda din öğretimi konusunda acil kararları almasına neden olmuştur. Zira, bazı aydınlar okullarda "dinler tarihi" formatındaki bir dersin okutulmasını ve bu dersi okutacak öğretmenlerin İlahiyat fakültelerinde yetiştirilmesi gerektiğini savunmuşlardır. Bazıları da Edep dersi gibi genel kültür dersleri ile insanların kendi dinlerini öğrenme ihtiyaçlarının karşılanamayacağı, eğer bu ihtiyacı devlet karşılamaz ise, bu vazifeyi farklı dini grupların yerine getireceği ile ilgili endişelerini dile getirmişlerdir. ${ }^{27}$ Devlet, ülkedeki dini durumu ve akademisyenlerin fikirlerini dikkate alarak çok önemli bir adım atmış bulunmaktadır. 14 Kasım 2014 tarihinde Kırgız Cumhuriyeti Cumhurbaşkanı'nın Kararnamesiyle “Kırgız Cumhuriyeti'nin 2014-2020 yılları için Din Alanındaki Devlet Politikasının Konsepti" onaylanmıştır. Bu belgede din eğitimini ilgilendiren kısım, "Kırgız Cumhuriyetinde Dini ve Dinbilimsel Eğitimi Reforme Etme Konsepti" olarak adlandırılıp, okulda din eğitimi ile ilgili kısım da "Örgün eğitim sistemi kapsamında 'dinbilimsel' eğitim verme, bu hususta ortaokul ve liselerde 'Din Kültürü Tarihi' dersini okutma" ${ }^{28}$ maddesi ile ifade edilmiştir.

26 Yusubov, Kırgizistan'da Din Eğitimi, 101-110.

27 Akramova, Kirglzistan'da Orto Mekteplerdeki “Adep Sabagı", 95-103. Dilaram Akramova, "Prepodavaniye religiyovedeniya v şkolah i vuzah Kırgızskoy Respubliki: problemı i puti ih reşeniya", Kırgızstan na sovremennom etape razvitiya. Analitiçeskiye zametki: Grajdanskoye obşestvo, migrasiya, islam, korrupsiya (Bişkek: Sentr sotsialnıh issledovaniy Amerikanskiy universitet $\mathrm{v}$ Sentralnoy Azii, 2008), 130-135. Timur Kozukulov, "V poiskah putey reşeniya problem islamskogo obrazovaniya v Kirgızstane", Kırgizstan na sovremennom etape razvitiya, 136-140. Kubatalı Topchubaev, Adep Dersi Öğretmenlerinin Yeterlilikleri (Oş İli Örneğinde Bir Alan Araştırması) (Ankara: Ankara Üniversitesi, Sosyal Bilimler Enstitüsü, Doktora Tezi).

28 Bk. BïUU, Religioznoe obrazovaniye v Kırgızstane: Medrese nujdayutsya v sroçnoy reforme, 14-15. 
Din alanındaki konseptin ilgili maddesini gerçekleştirme adına Kırgız Cumhuriyeti Bilim ve Eğitim Bakanlığı, Din Komisyonu ve Eğitim Akademisinin elemanlarından oluşan bir komisyon tarafından 2015 yılında Din Kültürü Tarihi ders programı hazırlanmıştır. "Din Kültürü Tarihi" dersi 20162017 eğitim-öğretim yılında ülke genelinde toplam 10 okula pilot uygulama olarak 9. sınıflarda okutulmuştur. 2018-2019 eğitim-öğretim yılında bu pilot uygulama, ülkenin 56 okulunda 9. sinıflarda devam ettirilmiştir. ${ }^{29}$ "Din Kültürü Tarihi" dersi seçmeli ders durumunda olup, dersin zorunlu ders olarak ülkenin müfredat programına dahil edilip edilmeyeceği hakkında henüz alınmış resmi bir karar ve net bir anlayış bulunmamaktadır.

Şimdi bu dersi amaç, derse ayrulan süre, ders öğretmeni, içerik, din eğitimi yaklaşımı, ders kitabı ve ders kitabında İslam tasviri, ders programında yansıtılan temel felsefe açısından kısaca incelemeye çalışalım.

Din Kültürü Tarihi dersinin gençlerin vatandaşlık bilincinin gelişmesine, vatansever olmalarına, milli örf ve adetlerine sahip çıkmalarına, manevi değerlere sahip insanlar olarak yetişmelerine katkı sağlayacağı beklenmektedir. Din Kültürü Tarihi dersinin temelini, "Kırgızistan toplumu çokkültürlü, çok dinli özelliğge sahip olduğundan dolayı, öğretim sürecinde herhangi bir dine odaklanmamalı" ilkesi oluşturmaktadır. ${ }^{30}$ Derste herhangi bir dinin öğretiminden ziyade, genel olarak din kültürü hakkında bilimsel bilgiler, dinler tarihi ve teorileri, laik devlet kavramı ve laiklik ilkeleri, din ve vicdan özgürlüğü gibi konuların öğretilmesi öngörülmektedir. Bir başka deyişle, "Din Kültürü Tarihi dersinde muayyen bir dinin eğitimi değil, bilimsel bir yaklaşımla din öğretimi yapılacaktır." anlayışı hakimdir. ${ }^{31}$ Nitekim dersin amaçlarında da bunu görmek mümkündür. Burada dersin amaçlarını şöylece ifade etmek mümkündür:

Bireylerin toplumsal ilişkilerde toleranslı, anlayışlı yetişmelerini sağlamak,

Öğrencilere ülkedeki laik kesim ve dindarlar arasındaki anlayış farklılıklarını, birbirlerine olan güvensizliklerini gidererek, hoşgörüyle yaklaşılması gerektiğini öğretmek,

Din Kültürü, Dinler Tarihi, Din ve Vicdan Hürriyeti konularında bilimsel bilgiler sunmak,

29 KR Prezidentine karaştuu din işteri boyunça mamlekettik komissiyası (KRDIMMK), "Din madaniyatının tarıhı" attuu pilottuk kurstun jıyıntıgı boyunça tegerek oturum jana seminar ötkörüü jönündö" (Erişim 03 Kasım 17).

30 Bk. IZP, InoZpress Perevodı zarubejnıh smi o Kırgızstane i Sentralnoy Azii, “Kırgızstan reformiruyet religioznoye obrazovaniye" (Erişim 16 Nisan 2016).

31 Gosudarstvennaya komissiya po delam religiy KR (GKDRKR), “o voprosah reformirovaniya religiovedçeskogo i religioznogo obrazovaniya v Kırgızskoy Respublike" (Erişim 16.10.17). 
Öğrencilerin eleştirel düşünce kabiliyetlerini geliştirmekle, laik toplumdaki dinî ve sosyal problemleri kavrayarak, dinî çoğulculuğu benimseyen, vatandaşlık eşitliği ve hukukî açıdan kültürlü bireyler olarak yetişmesini sağlamaktır. ${ }^{32}$

Yukarıdakilerden görüldüğü üzere, Din Kültürü Tarihi dersinin başlica amacı, gençlerin hoşgörülü, toleranslı ve anlayışlı vatandaşlar olarak yetişmelerini sağlamaktır. Ayrıca, dersin "dini bilgi verme, öğrencileri dini yönden geliştirme" gibi amacının olmadığı da anlaşılmaktadır. Bu husus "din konusunda genel olarak bilimsel bilgi verme" cümlesiyle sınırlı kalmıştır. Ayrıca, amaçlarda "dini çoğulculuk", "laik toplum", "dindar kesim ve laik kesim" gibi kavramlarının geçmesi dikkat çekmektedir.

Din Kültürü Tarihi dersi programı bir dönem için, haftada bir saat okutulmak üzere, toplam on altı saat olarak tasarlanmıştır. On altı saatin on iki saatini ders konuları oluştururken, dört saati öğretmenler için ayrılmış rezerv saattir. Bu reserv saatleri öğretmenler bazı konuları pekiştirmek veya gerekli gördükleri diğer konuları işlemek için kullanabilirler. Din Kültürü Tarihi dersine Tarih dersi öğretmenleri girebilmektedirler. Bunun sebebi de bu derste anlatılan dinlerin tarihi perspektifle ele alınmasıdır. ${ }^{33}$

Ders programı toplam 11 üniteyi kapsamakta olup, üniteler genellikle şu ana temalardan oluşmaktadır: Din, kültür, hoşgörülük ve laiklik gibi temel kavramların açıklanması mahiyetindeki genel konular, eskiçă̆ dinleri (Örneğin; Totemizm, Animizm, v.b.), ulusal dinler (Yahudilik, Konfüççülük, Şintoizm ve Taosizm), Budizm, Hiristyanlık ve İslam. ${ }^{34}$ Programda eski dinlerden başlayarak, modern dinlere kadar, tüm dinler tarihi perspektif ile ele alınmaktadır. Din Kültürü Tarihi dersinin içeriğinde genel konulara fazla yer verilmekle birlikte, İslam, Budizm, Hristyanlık gibi evrensel dinlere aşağı yukarı aynı oranda yer verildiğini görmek mümkündür. Konulara ayrılan oranların yüzdelerini ifade edecek olursak, karşımıza aşağıdaki sayılar çıkmaktadır:

Genel Konular - \% 37 (toplam 4 ünite),

Eskiçağ Dinleri - \% 18 (2 ünite),

Ulusal Dinler - \% 18 (2 ünite),

Budizm - \% 9 (1 ünite),

Hristyanlık - \% 9 (1 Ünite),

İslam - \% 18 (2 ünite)

Ders programında Kırgızistan'ın çokkültürlü, çok dinli yapısına vurgu yapılarak, muayyen bir dine odaklanmanın yanlış olduğu ileri sürülmektedir. Bir başka deyişle, hoşgörülük ilkesi yoğun bir şekilde öne çıkarılmaktadır.

32 Köylü-Bazarkulov, Din pedagogikası, 166-169.

33 Din Kültürü Tarihi ders programı hakkında geniş bilgi için bk. Colaliyeva, Kirgizistan Liselerinde Okutulan "Din Kültürü Tarihi" Dersi, 49-73.

34 Din madaniyatının tarıhı (9 klasstın okuuçuları üçün okuu kitebi), KR Bilim berüü jana ilim ministrligi, joop. red. N. U. Kurbanova, (Bişkek: JÇK “Altın print” basm., 2016), 129. 
Bundan hareketle, ders programının mezhepler üstü din eğitimi yaklaşımıyla hazırlandığını söylemek mümkündür.

Ders kitabını ele alacak olursak, kitabın ebad1 13×19,5 olup, 144 sayfadan oluşmaktadır. Kitapta anlatılan ünitelerin yoğunluğunu dikkate aldığımızda, kitap hacminin çok küçük olduğu göze çarpmaktadır. Kitap metin ağırlıklı olup, kitapta görsel malzemeler/materyaller az sayıda kullanılmıştır. Görsel malzemelerin de hem boyut, hem renklilik ve canlılık, hem de kullanılan malzemelerin taşıdıkları anlam yönünden birtakım eksikliklere sahip olduğunu belirtmek gerekmektedir. Ders kitabında geçen etkinliklere (sorular, ödevler, kısa sınavlar v. b.) gelince, kitapta bilgi ve kavrama düzeyindeki etkinliklere ağırlık verilmişken, daha üst düzey zihinsel çabayı gerektiren analiz, sentez ve değerlendirme mahiyetindeki etkinliklere az yer verilmiştir. Oysa günümüzdeki ders kitaplarının sadece bilgi odaklı olmaktan ziyade öğrencileri düşünmeye, eleştirmeye ve araştırmaya sevkedici mahiyette olmaları beklenmektedir.

Ders kitabında İslam dinine toplam konuların \%18'i ayrılmıştır. İslam konusunun tasvirinde teolojik açıdan yanlış olan bilgilerin yer alması dikkat çekmektedir. Konuyu bir örnekle açıklamak gerekirse, kitabın 81. sayfasında "İslam'ın Ana Kuralları" (Kırg.: Ислам дининин негизги эрежелери) kоnusu altında İslam inanç esasları anlatılmıştır. Metnin alt köşesinde İslam inanç esaslarının aşağıdaki şekildeki listesi verilmiştir:

İslam'ın dogmaları (senek ınanımdarı):

1. Tek tanrı hakkında öğreti (et-tevhid);

2. Tanrının hakikatliliğine ve adaletliliğine inanma (al-adl);

3. Muhammed'in ve ondan önce gelenlerin peygamberlik vazifelerini kabul etme (nübüvet);

4. Dirilmeye, Kiyamet gününe ve öbür dünyaya inanma (al-maad veya al-k1yama);

\section{5. İmamet/hilafet öğretisi. ${ }^{35}$}

Listedeki "Tanrının hakikatliliğine ve adaletliliğine inanma (al-adl)" ve "İmamet/hilafet öğretisi" maddelerinin inanç esaslarıyla hiç alakası yoktur. Burada Kırıgızistandaki ehli sünnet ve maturidi inancı olduğuna vurgu yap1lıp, sözü edilen imamet ve hilafet gibi kavramların şii anlayışını yansıttığı da söylenebilir. Dolayısıyla burada toplumdaki sosyal gerçekliğin dikkate alın-

35 Bk. Kırgızcası: İslamdın dogmaları (senek ınannımdarı)

1. Bir kuday jönündö okuu (at-tauhid).

2. Kudaydın akıykattuuluguna jana adilettüülügünö işenüü (al-adl);

3. Muhammeddin jana aga çeyinkilerdin paygambardık missiyasın taanuu (an-nubuvva);

4. Tirilüügö, Kıyamat kününö jana tigi düynögö işenüü (al-maad ili al-kıyama);

5. İmamat/halifat jönündö okuu. Bk. Din madaniyatının tarıhı, 81. 
madığ1 söylenebilir. Bununla birlikte, metinde öğrencilerin gelişim özelliklerine, dini bilgi alt yapılarına hiç uygun olmayan, spesifik dini terimler bolca kullanılmıştır. Örneğin, "kıyas" ve "icma" 36 gibi fikıh terimleri başta olmak üzere, "tarik", "vilaya", "sama" 37 gibi tasavvufi kavramlar da kullanılmıştır ki, bu kavramları öğrencilerin anlamaları bir tarafa, dersi veren öğretmenlerin bile anlamaları mümkün değildir. İslam tasvirinde bazı yanlış ve yetersiz bilgilerin verilmesinin nedeni muhtemelen, kitap yazarlarının da dini bilgi alt yapılarının yetersiz olmasıdır.

Son olarak, ders kitabında yansıtılan genel felsefe şu şekilde izah edilebilir; çokkültürlü Kırgızistan toplumunda farklı din mensuplarının bir arada hoşgörü ve barış içinde yaşaması, dini aşırılık ve terörizme karşı bir tavrın sergilenmesi, modern dünyada din-devlet ilişkilerinde laikliğin rolüdür. Bu hususta dikkatimizi çeken şey; dersin genel felsefesinde hoşgörü ilkesinin aşırı bir şekilde vurgulanmasıdır. Ortaya koyulan tespitlerden de anlaşılacağ1 üzere, Din Kültürü Tarihi dersine yönelik birtakım eksiklikler mevcuttur. Ülkede bu tür dersin ilk defa konulduğunu dikkate aldığımızda, bazı eksikliklerin olması doğaldır. Önemli olan, bu eksiklikleri tespit etmek ve bunların giderilmesine yönelik öneriler sunmaktır.

\section{Sonuç ve Değerlendirme}

Kırgızistan'da din-devlet ilişkileri konusunda bazı problemler olmakla beraber, diğer Orta Asya ülkelerine nazaran, ülkede din ve devlet ilişkilerinde bir dialogdan söz etmek mümkündür. Böylece, vatandaşların din ve vicdan özgürlüğü önemsenmekte, dini gruplar devletin ilgili kurumlarının izni doğrultusunda, rahat bir şekilde faaliyetlerini yürütebilmektedirler. Bununla birlikte, son zamanlarda devletin dini alanla daha yakından ilgilenmeye başladığı ve bazı düzenlemelere başvurarak, bu alanda etkin pozisyon almaya çalıştığ1 görülmektedir.

Okullarda uygulanan din derslerinin tarihi gelişimine gelince, bağımsızlğın ilk yıllarından başlayarak bugüne kadar farklı denemeler (İman dersi, Edep dersi) söz konusu olmuştur. Ancak bu dersler din eğitimi meselesini çözememiştir. Günümüzde Edep dersi Kırgızistan okullarında zorunlu olarak okutulmaktadır. Edep dersinde de dini bilgilerden ziyade, genel kültür mahiyetindeki bilgiler verilmektedir. Dini konulara kısmen yer verilmesine rağmen ders, öğrencilerin dini bilgilere olan ihtiyacını karşılamamaktadır.

Din dersi konusundaki son deneme ise, Din Kültürü Tarihi dersi olup, bu ders de 2016-2017 eğitim-öğretim yılından itibaren Kırgızistan'ın bazı okullarında 9. sınıflarda seçmeli ders olarak okutulmaktadır. Dersin zorunlu ders

36 Din madaniyatının tarıhı, 87.

37 Din madaniyatının tarıhı, 86. 
olarak ülkedeki eğitim müfredatına dahil edilip edilmeyeceği şu an belli olmamakla birlikte, böyle bir dersin okullarda okutulmaya başlamasının önemli bir adım olduğu söylenebilir. Bunun yanı sıra, yeni bir uygulama olması nedeniyle, bu dersin birtakım eksiklikleri vardır.

Din Kültürü Tarihi dersi programı mezhepler üstü din öğretimi yaklaşımı ile hazırlanmıştır. Bu anlayışın sonucu olarak, ders içeriğinde tüm dinlere aşağı-yukarı aynı oranda yer verilmektedir ve tarafsızlık ilkesine önem verilmektedir. Günümüz dünyasında farklı kültürler iç içe yaşamaktadır, bu sebeple öğrencilere tarafsızlığı ve hoşgörüyü kazandırmak önemlidir. Ancak, benimsenen mezhepler üstü yaklaşım bazı problemleri de beraberinde getirmektedir. Şöyle ki, bazı din eğitimcileri, bu tür yaklaşım ile yapılan din öğretiminin bir tarih ve genel kültür dersine benzeyeceğini ve yeni neslin yetişmesine katkıda bulunma yeteneğini kaybedeciğini iddia etmektedirler. ${ }^{38}$ İkinci olarak, mezhepler üstü yaklaşımla din öğretimi gerçekleştirilen bazı gelişmiş ülkelerde ${ }^{39}$, din dersleri ülkenin ya da bölgenin özelliğine göre, çoğunluğun mensup olduğu din ya da mezhep ağırlıklı olarak okutulmaktadır. ${ }^{40}$ Bir başka deyişle, her ne kadar çokkültürlülük fikri hakim olsa da, çoğunluğun inandığı dine ağırlık verilmesi esastır. Kırgızistan nüfusunun yaklaşık \%90’1 Müslümandır, bundan dolayı Din Kültürü Tarihi dersi içeriğinin büyük kısmı (\%7080) İslam konusuna ayrılmalıdır. Zira, mezhepler üstü yaklaşımın dünyadaki mevcut uygulanış şekli böyledir. ${ }^{41}$ Gerek tarih gerek toplumsal yapı, gerek

38 John Shepherd, "İslam ve Din Eğitimi (Mezhebe/Dine Dayalı Olmayan Yaklaşım)", Çeviren Bekir Demirkol, Din Öğretimi ve Din Hizmetleri Semineri (8-10 Nisan 1988), (Ankara: Din İşleri Başkanlığı Yayınları, 1991), 371-372 akt. Mehmet Zeki Aydın, “Okulda Din Dersi Tartışmaları (Türkiye'de Din Dersinin Tarihi, Teorik Yapısı, Bazı Ülkelerle Karşılaştırılması)", Cumhuriyet Üniversitesi Illahiyat Fakültesi Dergisi 11/2 (Aralık 2007), 19-20.

39 Örnek olarak İngiltere ve Türkiye'yi söyleyebiliriz. İngiltere çokkültürlü ve çok dinli nüfüsa sahip bir ülkedir, bundan dolayı bu ülkede din dersleri mezhepler üstü yaklaşımla okutulmaktadır. Ancak, İngiltere' de her ne kadar dini çoğulculuk anlayışı benimsense de din derslerinin içeriğinde çoğunluğun dini olan ve ülkenin tarihsel arkaplanını oluşturan Hıristiyanlığa ağırlık verilmektedir. Örneğin, tüm devlet okullarında zorunlu olan toplu dua Hristiyan dinine göre yapılmakta, din dersi içeriğinin \%50'si Hıristiyanlığa ayrılmaktadır. Bu yaklaşımı uygulayan diğer ülke de Türkiye'dir. Türkiye nüfusunun \%99'u Müslümandır, ancak ülkede laiklik ilkesi hâkim olduğu nedeniyle, okulda din öğretimi mezhepler üstü yaklaşım ile gerçekleştirilmektedir. Din dersi programının temelini İslam dini, Kur'an ve sünnetin ortaya koyduğu temel ilkeler oluşturmaktadır. Programda diğer dinlere de yer verilmektedir, ancak ülkedeki güncel dini durum göz önünde tutularak, diğer dinlere az yer ayrılmaktadır. Bilgi için bk. Recep Kaymakcan, Günümüz İngilteresinde Din Ĕ̆itimi (İstanbul 2004); Suat Cebeci, Din Eğitimi Bilimi ve Türkiye'de Din Ĕ̆itimi (Ankara: Akçă̆ Yayınları, 2005); Nurullah Altaş, “Ortaöğretimde Din Eğitimi”, Din Eğitimi, ed. Mustafa Köylü-Nurullah Altaş (İstanbul: Ensar Neşriyat Yayınevi, 2017).

40 Aydın, "Okulda Din Dersi Tartışmaları", 41.

41 Dünya ülkelerinde din öğretimi uygulamarı hakkında geniş bilgi için bkz.: Mustafa Köylüİbrahim Turan, Karşılaştırmalı Din Eğitimi (Ankara: Nobel Akademik Yayıncılık Eğitim Danışmanlık Tic. Ltd. Şti., 2014); Mehmet Zeki Aydın, Avrupa Birliği Ülkelerinde Din Eğitimi ve Türkiye ile Karşılaştırılması, Diyanet Avupa Dergisi 68 (Aralık 2004), 14-21. 
kültürel yakınlık bakımından Kırgızistan'la birçok ortak yönü bulunan Türkiye' deki “Din Kültürü ve Ahlak Bilgisi” dersi örneği de bu şekildedir. Dolayısıyla, Din Kültürü Tarihi dersi, bu açıdan yeniden gözden geçirilmeli ve öğrencilere kendi dinleri hakkında doğru bilgi kazandırmayı da amaçlamalıdır. Bu ders üzerinden böyle bir değişiklik yapılamazsa, öğrencilerin kendi dinlerini öğrenebilecekleri seçmeli özel bir din dersi de düşünülmelidir. Öğrencilerin kendi dinlerine ait sağlıklı ve yeterli bir dini bilgi alt yapıları olmadan başka dinler hakkında gereğinden fazla bilgiye maruz kalmaları dini gelişimleri açısından da doğru olmasa gerektir.

Din Kültürü Tarihi dersine ayrılan süre haftada sadece bir saattir. Ders süresinin yetersiz olduğu ortadadır, zira derste çok geniş konular ele alınmaktadır ve bu sınırlı süre içinde tüm konuların verimli bir şekilde işlenmesi zordur. Bununla birlikte, dersin 9. sınıfta verilmeye başlaması soru işaretini getirmektedir. Zira, çoğu ülkelerde din eğitimi ilkokuldan itibaren verilmeye başlamaktadır. Kırgızistan şartlarını dikkate alarak, bu dersin en azından 5 . sınıftan itibaren okutulmaya başlaması yerinde olacaktır. Ders öğretmeni konusunda da problemler mevcuttur. Daha önce de belirtildiği gibi, Din Kültürü Tarihi dersini Tarih dersi öğretmenleri vermektedir. Her ne kadar Din Kültürü Tarihi ve Tarih dersinin arasında bazı ortak konuları olsa da Din Kültürü Tarihi dersini din alanında mesleki eğitim almış diplomalı uzmanların okutması isabetli olacaktır. Zira, Kırgızistan'daki İlahiyat fakülteleri bu dersi verebilecek nitelikteki mezunları yeterli sayıda vermektedirler. Din Kültürü Tarihi ders kitabının içeriğini ve ebadını yeniden gözden geçirmede fayda bulunmaktadır. Ayrıca, ders kitabındaki etkinlikleri (metin içinde ve sonunda verilen sorular, ödevler, kısa sınavlar, v.b.) düzenleme sırasında daha çok analiz, sentez ve değerlendirme düzeylerindeki hususlara ağırlık verilmelidir. Bunlara ilaveten, monoton didaktiğin sınırlarından çıkarak, uygulamalı ve sınıf dişı etkinliklere daha çok yer verilmelidir. Sonuç olarak, Kırgızistan' da örgün eğitim kapsamında dini konu edinen bir dersin okutulmaya başlaması önemli bir gelişme olmakla beraber, bu dersi felsefi, yöntemsel ve içeriksel olmak üzere, farklı bakış açılardan incelemek ve en uygun din dersi modelini geliştirmek gerekmektedir. Bu ders, benimsenen din öğretimi felsefesi ve modeli, eğitim programı, ders kitabı, öğretmen yetiştirme vb. açılardan yeniden gözden geçirilmelidir. Bu istikamette, ülkedeki mevcut dini, sosyal ve siyasi durum dikkate alınarak, yeni ders programı ve ders kitabı oluşturulmalı, öğretmen eğitimleri gözden geçirilmelidir. Bu konuda gelişmiş ülkelerin ve özellikle Türkiye'nin tecrübelerinden de faydalanılabilir. 


\section{Kaynakça}

Akramova, Dilaram. "Prepodavaniye religiyovedeniya v şkolah i vuzah Kırgızskoy Respubliki: problemı i puti ih reşeniya". Kırgızstan na sovremennom etape razvitiya. Analitiçeskiye zametki: Grajdanskoye obşestvo, migrasiya, islam, korrupsiya. Bişkek: Sentr sotsialnıh issledovaniy Amerikanskiy universitet v Sentralnoy Azii, 2008.

Akramova, Dilaram. Kırgızistan'da Orto Mekteplerdeki "Adep Sabagı" Dersinde Din Eğitimi İle İlgili Amaçlarm Gerçekleşme Düzeyi (Oş Örneği). Ankara: Ankara Üniversitesi, Sosyal Bilimler Enstitüsü, Doktora Tezi, 2006.

Aktaş, Hamza. "Kırgızistan'da Son Dönem Din Eğitimi Gelişmeleri”. Akademik Sosyal Araştırmalar Dergisi 4/36 (2016), 233-257.

Altaş, Nurullah. "Ortaöğretimde Din Eğitimi". Din Eğitimi. ed. Mustafa Köylü-Nurullah Altaş. 190-221. İstanbul: Ensar Neşriyat Yayınevi, 8. Basım, 2017.

Aydar, Hidayet. "Kırgızistan'da Dindarlaşma Tirendi; Problemler, Öneriler". Türk Dünyası Bilgeler Zirvesi: Gönül Sultanları Buluşması Sempozyum Bildiri Kitabı (Eskişehir, 26-28 2013 Mayıs). 497-536. Eskişehir: Türk Dünyası Kültür Başkenti Ajans1, 2014.

Aydın, Mehmet Zeki. “Avrupa Birliği Ülkelerinde Din Eğitimi ve Türkiye ile Karşılaştırılması". DiyanetAvupa Dergisi 68 (2004).

Aydın, Mehmet Zeki. “Okulda Din Dersi Tartışmaları (Türkiye'de Din Dersinin Tarihi, Teorik Yapısı, BazıÜlkelerle Karşılaştırılması)". Cumhuriyet Üniversitesi İlahiyat Fakültesi Dergisi 11/2 (Aralık 2007).

BİIUM, "Bulan" institut innovatsıy dlya ukrepleniya mira. Religioznoe obrazovaniye v Kırgızstane: Medrese nujdayutsya v sroçnoy reforme. "Bulan" institut innovatsı dlya ukrepleniya mira, 2017. www.bulaninstitute.org.

BIPI, The Bulan Institute for Peace Innovations. "A Situational Analysis Of Islamic Education of Citizens Of The Kyrgyz Republic: Studyıng Abroad (Report by the Bulan Institute for Peace Innovations"). (September 2018). Erişim 30 Temmuz 2019. https://bulaninstitute.org/a-situational-analysis-islamiceducationabroad-report/

Büyükalaca, Orhan Nadir. Kırgızistan'da Din Eğitimi ve Kırgızistan Müslümanları Dini İdaresi. Ankara: Ankara Üniversitesi, Sosyal Bilimler Enstitüsü, Yüksek Lisans Tezi, 2003.

Cebeci, Suat. “Kırgızistan'da Dini Durum ve Sovyet Sonrası Dini Gelişmeyi Besleyen Etkenler". MANAS Sosyal Araştırmalar Dergisi 5/3 (2016), 103-117.

Cebeci, Suat. Din Eğitimi Bilimi ve Türkiye'de Din Eğitimi. Ankara: Akçağ Yayınları, 2. Basim, 2005.

Cebeci, Suat. Kırgızistan'da Dini Durum ve Din Ĕ̆itimi: Durum Analizi ve Öneriler (Araştırma Raporu). Kırgizistan - Türkiye Manas Üniversitesi, 2014.

Cihan, Ahmet. "Kırgızistan'da Din Eğitimi Veren Kurumlar". İslam Araştırmaları Dergisi 14 (2005), 111-124.

Colaliyeva, Cazgül. "Din Öğretimi Temelleri: Kırgızistan Örneği". MANAS Sosyal Araştırmalar Dergisi 7/3 (2018), 279-295. 
Colaliyeva, Cazgül. Kırgızistan Liselerinde Okutulan "Din Kültürü Tarihi" Dersi Programının Incelenmesi: Bişkek Örneği. Bişkek: Kırgızistan-Türkiye Manas Üniversitesi, Sosyal Bilimler Enstitüsü, Yüksek Lisans Tezi, 2018.

Çotayev, Z. D. “Vliyaniye religiyoznogo faktora na sotsialno-politiçeskuyu situatsiyu v Kırgızskoy Respublike: Sotsiologiçeskoe issledovaniye". PDF: Gosudarstvennay komissiya po delam religiy Kırgızskoy Respubliki, 2016. http://religion.gov.kg/wp-content/uploads/2016/.pdf.

Çotonov, Özübek. Iyman sabagı: Filosofiyalık, publitsistikalık oy-tolgoolor. Bişkek: Mega mediya, 2004.

Din madaniyatının tarıhı (9 klasstın okuuçuları üçün okuu kitebi), KR Bilim berüü jana ilim ministrligi, joop. red. N. U. Kurbanova. Bişkek: JÇK “Altın print" basm., 2016.

I-X klasstarda 1yman sabagın okutuunun boljolduu programması (1992-1993-okuu j1lı üçün), tüz. B. Nurunbetov, M. Bayımbetov, A. Köçkönov, A. Tölönbaev. Oş, 1992.

IZP, InoZpress Perevodı zarubejnıh smi o Kırgızstane i Sentralnoy Azii, “Kırgızstan reformiruyet religioznoye obrazovaniye”. Erişim 16 Nisan 2016. http://inozpress.kg/news/ view/id/48338.

Kaymakcan, Recep. Günümüz İngilteresinde Din Eğitimi. İstanbull, 2004.

Konstitutsiya Kırgızskoy Respubliki ot 27 iyunya 2010 goda. Statya 1, punkt 1. Erişim 22 Mayis 2018. www.ilo.org/dyn/natlex/docs/ELECTRONIC/87546/100422/F1508978012/KGZ87546.

Kozukulov, Timur. “V poiskah putey reşeniya problem islamskogo obrazovaniya $\mathrm{v}$ Kirgızstane", Kırgızstan na sovremennom etape razvitiya. Analitiçeskiye zametki: Grajdanskoye obşestvo, migrasiya, islam, korrupsiya. Bişkek: Sentr sotsialnıh issledovaniy Amerikanskiy universitet v Sentralnoy Azii, 2008.

Köylü, Mustafa - Turan, İbrahim. Karşılaştırmalı Din Eğitimi. Ankara: Nobel, 2014.

Köylü, Mustafa - Bazarkulov, Sayfulla. Din Pedagogikası. Bişkek: Kırgız-Türk "Manas” Universiteti Basılmaları, 2018.

KRDIMKK, Kırgız Respublikasının Din işteri boyunça mamlekettik komissiyasının rasmiy saytı. Erişim 15 Aralık 2019. http: //religion.gov.kg/ru/religion_organization/registered/all.

MinYustKR, Ministerstvo Yustitsii Kırgizskoy Respubliki. "Konseptsiya gosudarstvennoy politiki v religioznoy sfere na 2014-2020 god1, utverjdennaya Ukazom Prezidenta KR ot 14.11.2014 goda". Erişim 06 Ocak 2020. http://cbd.minjust.gov.kg/act/view/ru-ru/68294.

Mırzabaev, Mametbek. Kırgııistan'da Din-Devlet İlişkileri. Ankara: Ankara Üniversitesi, Sosyal Bilimler Enstitüsü, Doktora Tezi, 2009.

Sarıgulov, Dastan. Iyman sabagı (tüpkü tüşünüktör). Bişkek, 2004.

Shepherd, John. "İslam ve Din Eğitimi (Mezhebe/Dine Dayalı Olmayan Yaklaşım)". çev. Bekir Demirkol. Din Öğretimi ve Din Hizmetleri Semineri (8-10 Nisan 1988). Ankara: Diyanet İşleriYayınları, 1991.

Topchubaev, Kubatalı. Adep Dersi Öğretmenlerinin Yeterlilikleri (Oş İli Örneğinde Bir Alan Araştırması). Ankara: Ankara Üniversitesi, Sosyal Bilimler Enstitüsü, Doktora Tezi. 
Yılmaz, Hüseyin. "Kırgızistan'da Misyonerlik ve Din Eğitimi”. Cumhuriyet Üniversitesi İlahiyat Fakültesi Dergisi 11/1 (Haziran 2007), 91-128.

Yusubov, Elvin. Kırgızistan'da Din Eğitimi. İstanbul: Marmara Üniversitesi, Doktora Tezi, 2016. 


\section{Attempts to Introduce Religion Courses in Schools of Kyrgyzstan in the Years of Independence and Latest Developments}

\section{(Extended Abstract)}

The declaration of independence was a turning point in the socio-economic, political and cultural life of Kyrgyzstan. There have been important developments, especially in religious institutions. From the first days of independence, issues related to freedom of religion and conscience have begun to be discussed actively among the Kyrgyz politicians. The general attitude of statesmen about religion emerged as emphasizing that the oppression against religion in the Soviet period was wrong, so religion began to take on greater significance in the social life of the country. Religion-state relations have started to be regulated legally with a number of national and international laws, agreements, and decrees under the principles of democracy. In addition, it was emphasized, in the first articles of the Constitution, that the country adopted secularism. These legal regulations ensured the freedom of citizens in the religious field. We can say that there have been serious developments in the religious field in terms of quantitative and qualitative aspects in general. There is also a rapid increase in the level of religiousness of the Kyrgyz people. Thus, there has been a significant improvement in subjects such as the level of religious knowledge of the people, religious tendencies, view of religious movements and groups, their attitude towards religious people and institutions, their attitude towards religious orders and prohibitions, and their religious worship.

As for religious education in Kyrgyzstan, the question: "Whether or not to give religious education in the formal education institutions?" has been constantly discussed from the first days of independence. The discussions arise from the application of the concept of "secularism" in the country. Those, who oppose religious education in the formal education institutions, argue that it is not possible to provide religious education in state institutions due to the secular nature of the country. According to the opinion of this part of people, religion and state institutions should be separated from each other in the secular state. Those who advocate that religious education should be given in state institutions, interpret secularism as "the state's fair attitude towards all religious groups in the country". For this reason, the state is expected to provide its citizens a religious education correctly. Despite such discussions, there has been an awareness that religious education in the country's formal educational institutions is an important factor for the country's security, especially in recent years. Thus, there have been different attempts to teach religion courses from the first years of independence until nowadays. 
The first attempt was "Iyman" (Faith) course. Iyman course was taught as an elective course in 1992-2002, and as a compulsory course in the 2002-2003 academic years in Kyrgyzstan's schools. The content of the Iyman course program was composed of moral principles, spiritual values, customs, human values, and virtues of the Kyrgyz nation. Religious content was also included in the program, but not systematically. Information about religion was scattered throughout the program and was given within the framework of moral education in general. Accordingly, the course aimed at moral education within the framework of general culture rather than a religious course. As a result of the lack of a systematic program, educators who were familiar with the subject and other problems, the Iyman course failed to achieve the desired success. Moreover, the different meanings attributed to the concept of "Iyman" in the title of the lesson led to the discussion concerning its content. Consequently, the Iyman course was changed as the "Adep" (Ethics) course in 2004 by the Ministry of Education of Kyrgyzstan.

The Adep course is being taught as a compulsory course in Kyrgyzstan's schools since the 2004-2005 academic year. First of all, it should be noted that the Adep lesson is not a religious lesson, but a general culture lesson. Themes concerning religion in the curriculum are also less than those in Iyman course, and Islam is considered only as an element of culture. The topics included in this course are designed to contribute to the moral development of students in general. However, the program provides sufficient and systematic information neither about Islam nor about other religions. Therefore, it is a fact that this course does not meet the need of students for religious information, since some religious topics given unsystematically in the Adep course are quite insufficient.

As a consequence of all this, the issue of teaching a religious course in public schools has come to the agenda again. With the initiative of the previous President of the Kyrgyz Republic and with the contributions of some state institutions, a new course called "Din Madaniyatini Tarihi" (History of Religious Culture) began to be taught in some schools of the country since 20162017 academic year. At this moment it is not yet clear, whether the course will be included in the curriculum as a compulsory subject or not, it can be said, that it is an important step to start teaching such course in schools, though, the course has some shortcomings as it is a new application.

The curriculum has been prepared with the intercultural religious education method, and the principle of neutrality is emphasized. Different cultures live together in today's world, so it is important to teach students neutrality and tolerance. However, the intercultural religious education approach causes some problems. Some religious educators claim that religion courses lose the ability to contribute to the upbringing of the new generation if this approach is pursued. Other shortcomings of the History of Religious Culture 
course are the lack of time allocated to the lesson and the problems regarding the teacher.

There are many studies on formal religious education in Kyrgyzstan. In these studies, all stages of formal religious education in the country were analyzed extensively, but the issue of religious education at school was not thoroughly examined. Also, recent developments in this field are not studied in these works. In this article, the theme of religious education in Kyrgyzstan's schools and recent developments in this field are examined. In this respect, this work aims to contribute to the field. 